\title{
Typhoons in the Philippine Islands, 1901-1934
}

\author{
Pedro Ribera $^{1, *}$, Ricardo García-Herrera ${ }^{2}$, Luis Gimeno ${ }^{3}$, Emiliano Hernández ${ }^{2}$ \\ ${ }^{1}$ Dpto. de Ciencias Ambientales, Universidad Pablo de Olavide, Carretera de Utrera, Km 1, 41013 Sevilla, Spain \\ ${ }^{2}$ Dpto. Física de la Tierra II, Facultad de Ciencias Físicas, Universidad Complutense de Madrid, Ciudad Universitaria, \\ 28040 Madrid, Spain \\ ${ }^{3}$ Dpto. Física Aplicada, Universidad de Vigo, Facultad de Ciencias de Ourense, As Lagoas s/n, 32004 Ourense, Spain
}

\begin{abstract}
A chronology of typhoons and storms in the Western North Pacific is presented, based on the previous work of Miguel Selga, a former director of the Manila Observatory. It includes data about 863 typhoons, storms and depressions over the western Pacific area between 1901 and 1934. The chronology provides information covering a wide area, from Guam to the Gulf of Tonkin and from the equator to Japan. The resulting typhoon series has been included in a database, which is freely accessible, and annual typhoon occurrence and trajectories are also shown. A comparison of the typhoon passage frequency over the Philippine area with a previously available chronology was made to assure the validity of Selga's observations, showing good agreement.
\end{abstract}

KEY WORDS: Climate variability · Typhoons · Western Pacific Ocean

Resale or republication not permitted without written consent of the publisher

\section{INTRODUCTION}

Tropical cyclones cause extensive human and economic losses. An increasing number of publications have addressed this topic, in order to gain an understanding both of the mechanisms responsible for their frequency and intensity (i.e. Landsea et al. 1996, Chang \& Shin 2000) and of their environmental, social and economical consequences (i.e. Diaz \& Pulwarty 1997).

The high variability in tropical cyclone frequency, with significant millennial, multidecadal and interannual oscillations (Landsea et al. 1996, Liu \& Fearn 2000, Elsner \& Bossak 2001), indicates that there is not a simple mechanism responsible for cyclone development. Relationships between Western North Pacific (WNP) tropical cyclones and climate oscillations such as the El Niño-Southern Oscillation (ENSO) or the Quasibiennial Oscillation (QBO) have been described in the literature (Chang 1995, 2000, Wang \& Chang 2002). In particular, the source region of WNP typhoons seems to be sensitive to the ENSO (Chang 1985), and significant interdecadal changes in their trajectories in the last 5 decades have been documented (Ho et al. 2004).
One of the biggest problems when studying tropical cyclones is the length and resolution of the instrumental series. The series are relatively short, approximately 50 to $60 \mathrm{yr}$ at best. Thus, various efforts are being made to extend these series back in time, using historical data or natural proxies (Spennemann \& Marschner 1994, Doyle \& Gorham 1996, Chang \& Shin 2000, Liu \& Fearn 2000, Donnelly 2001, Liu et al. 2001, Garcia-Herrera et al. 2005). If we focus our attention on the WNP basin, there are 3 major databases: the 'US Joint Typhoon Warning Center's Best Track', which begins in 1945 (available at http://www.npmoc.navy. mil/); the 'Regional Specialized Meteorological Center-Tokyo Typhoon Center database', with reliable data since 1951 (available at http://www.jma.go.jp/ JMA_HP/jma/jma-eng/jma-center/rsmc-hp-pub-eg/ RSMC_HP.htm); and 'The China Year Typhoon Book database', in existence since 1945, although reporting only typhoons which made landfall in China. Data previous to 1945 are limited to the annual number of landfalling typhoons in certain areas, such as China, where there is a series on the annual number of landfalling typhoons since 1880 .

In this paper, data for a $30 \mathrm{yr}$ period, initially catalogued by the Spanish Jesuit Miguel Selga, are 
described and made available. Selga's (1935) original work consists of a chronology of typhoons in the vicinity of The Philippines lasting from the 16th century to 1934; it is divided into 2 periods: 1564-1900 and 1901-1934. The first period contains mostly reports from historical records and has been analyzed in R. Garcia-Herrera et al. (unpubl.). The second period includes mostly direct instrumental observations made by the Manila Observatory and its associated network. The present paper analyses the 1901-1934 period. During this period, the Manila Observatory, founded and supervised by the Jesuits, acted as the meteorological agency of the islands (Udías 2003). In the final section of our paper, an analysis of the geographical probability distribution of typhoon-passage frequency was performed, with the aim of detecting differences between Selga's data and analyses conducted in the instrumental period. The recent work by Ho et al. (2004) was used to provide a comparison with Selga's chronology.

\section{DATA AND METHODS}

The data presented and analyzed in this paper have been extracted from the Catalogue of Typhoons 1348-1934, which is an addendum to Selga (1935). It includes information for 863 events, of which 619 are included as typhoons, the others being catalogued as storms or depressions. The starting date of 1901 was selected in this study, because this is then when the US Administration entrusted control of the newly created Philippines Weather Bureau to the Manila Observatory. The meteorological service was established with 9 first-class, 25 second-class and 17 third-class stations, though not all of them were actually operational. Additionally, meteorological information was shared among different services/observatories, including ones located in Taiwan, Shanghai and Manila (Udías 2003). Thus, the chronology is not limited to The Philippines but covers most of the WNP.

All the events listed were direct observations from one of the observatories; their descriptions include complete dating information. As an example, 4 reports have been included in Table 1 . The first report describes a typhoon that crossed the Visayas and entered the China Sea, and it provides an instrumental measurement of sea-level pressure. The second report includes a much more detailed description of the typhoon trajectory and some of the effects caused by this typhoon. In addition, it includes 2 measurements of sea-level pressure at 2 different positions of the typhoon trajectory. In the third record, some information about the typhoon trajectory is provided, but no instrumental information is included. Finally, the last record is an example of a storm, with some information about its trajectory.

Records of more than $30 \%$ of the typhoons (264) include some instrumental information, usually pressure data. The complete information provided by Selga has been digitized, including information about dating, the areas most affected, sources, intensity of the phenomenon and the original description included by Selga. The complete database is accessible at http:// www.ucm.es/info/tropical/.

Selga's chronology includes information about at least 1 location, usually more, where the typhoons were observed, so this allows us to characterize, at least partially, the typhoon tracks. We have used 2 different approaches to identify tracks. (1) An approxima-

Table 1. Examples of different kinds of reports included in the Selga chronology. Reports of 3 typhoons, (1) and (2) with instrumental data; and (3) without instrumental data; and (4) 1 report of a storm

\begin{tabular}{ll}
\hline Date & Description \\
\hline $\begin{array}{l}\text { (1) 15-16 May 1901 } \\
\text { Typhoon }\end{array}$ & $\begin{array}{l}\text { A depression crossed Visayas: intense typhoon in the China Sea: barometric minimum of 728.46 mm on } \\
\text { board the 'Esmeralda' }\end{array}$ \\
$\begin{array}{l}\text { (2) } 8 \text { Nov } 1912 \\
\text { Typhoon }\end{array}$ & $\begin{array}{l}\text { This typhoon formed near the Western Carolines. It moved W by N with great velocity. The center of } \\
\text { the storm, not fully developed yet, passed close to Surigao, over northern Bohol, across Cebu, a few } \\
\text { miles to the south of the capital, across the central part of Negros, and across the southernmost part of }\end{array}$ \\
& $\begin{array}{l}\text { Panay by the south of Iloilo and San Jose, Antique. The steamer 'Marinduque' ran aground on a coral } \\
\text { reef in the Dumaran Channel. Her barometric minimum was 739.40 mm and she experienced a central } \\
\text { calm of about 16 min. After passing the island of Dumaran and the northern part of Palawan, the storm } \\
\text { crossed the China Sea without changing its direction nor diminishing its velocity and reached Annam } \\
\text { with such fury that it was considered the most violent that had passed over Nhatrang within the }\end{array}$ \\
& $\begin{array}{l}\text { memory of man. The barometric minimum at Nhatrang was 729.9 mm } \\
\text { A typhoon formed over the Pacific, crossed the Balintang Channel, recurving northeastward to the } \\
\text { south of Batanes and moved back northwest, crossing southern Formosa }\end{array}$ \\
(3) 3-10 Aug 1919 & $\begin{array}{l}\text { This depression formed E of the Visayas, moved NNW and W, passed north of Luzon, recurved to the } \\
\text { Typhoon }\end{array}$ \\
(4) 7-14 Oct 1916 and crossed the southern part of Formosa \\
Storm
\end{tabular}


tion of each typhoon trajectory was estimated using the coordinates of every point where it was reported by means of a curve that was fitted to pass through all those points as smoothly as possible. Trajectories were not expected to be complete, and probably some areas affected by the typhoon were not included, but they included all the information available in the chronology. Individual trajectories were included online for all the typhoons in the database. (2) We estimated the spatial distribution of the typhoon trajectories using maps with $5^{\circ}$ latitude by $5^{\circ}$ longitude boxes accounting for the frequency of typhoons traversing through them. Selga's chronology is very much centered on typhoons affecting The Philippines. Thus, the chronology tends to contain typhoons that included this archipelago in their trajectories. In order to compare this chronology with analyses done for a more recent period over this area, we computed the geographical distribution of typhoon passage frequency as done in Ho et al. (2004), defined as the percentage value obtained by dividing the observed frequency in a box by the total number of typhoon formations in the whole area considered. This percentage indicates the probability that a typhoon will appear in each $5^{\circ} \times 5^{\circ}$ area.

\section{RESULTS}

Fig. 1 shows the annual number of typhoons occurring over the whole area analyzed between 1901 and 1934. The mean number of typhoons per year was slightly higher than 18, and it remained approximately constant throughout the whole period with no significant trends. The annual number of typhoons and tropical storms (of at least $18 \mathrm{~m} \mathrm{~s}^{-1}$ ) formed in the whole WNP basin was about 27 (Yumoto \& Matsuura 2001), and the annual number of typhoons having winds of at least $33 \mathrm{~m} \mathrm{~s}^{-1}$ was around 17 (http://www.aoml.noaa. gov/hrd/tcfaq/E10.html). Furthermore, this number shows a moderate interannual variability linked to the ENSO (Wang \& Chang 2002) and the QBO (Chan 1995). Selga's chronology is likely to have missed several typhoons yearly because of its lack of observational coverage over the whole basin; nevertheless, it seems to have overestimated the number of typhoons in the region, and it was not very sensitive to interannual variability. Most probably, overestimation is due to biases produced by errors such as considering as independent 2 or more typhoons reported at different observatories but representative of a single event. However, the main reason for overestimation could be the inclusion of storms as fully developed typhoons, but the difference between Selga's data and modern instrumental data is not as big as could be expected. The lack of instrumental data in Selga's work makes it

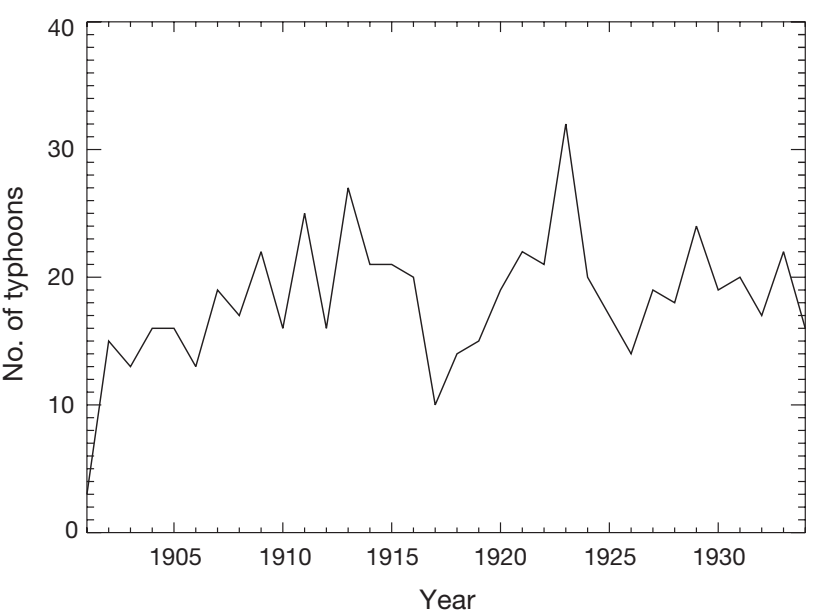

Fig. 1. Annual number of typhoons recorded over the Western Pacific area 1901-1934. Total $=619$

difficult to know how many of the systems called 'typhoons' by Selga were what we define today as a typhoon (systems with winds $\geq 33 \mathrm{~m} \mathrm{~s}^{-1}$ ) and how many were storms or depressions. However, an estimation can be made using the approximately $30 \%$ (256 of 619) of Selga's typhoons for which a measurement of atmospheric pressure was provided. According to Dvorak $(1975,1984)$, a central pressure of at most $976 \mathrm{mb}$ is necessary to support minimal typhoon intensity for the WNP. In 139 of Selga's 256 typhoons, the pressure was lower than $976 \mathrm{mb}$, although it is important to note that the atmospheric pressure referenced in Selga's work could have been measured in any part of the typhoon. This estimation shows that a minimum of $55 \%$ of the so-called 'typhoons' by Selga were really typhoons, which suggests that Selga might have overcounted the number of typhoons.

Fig. 2 shows the typhoon trajectories included in Selga's chronology. It agrees with recent chronologies in identifying late summer and early autumn (July to October) as having the highest number of typhoons. It also shows the area covered by the Manila Observatory, with observations from Guam to the Gulf of Tonkin and from the equator to Japan, and includes most of the continental coast of eastern Asia. The quality of the estimated typhoon trajectories depends very much on the number of reference points available. When only 1 point is given in the text, an asterisk is used to locate the typhoon on the map. Trajectories made from only 2 points result in unrealistic straight trajectories, such as that in October 1932 (Selga 1935, p. 4-10), which followed a straight line from the Western Carolines to the NE corner of the analyzed area:

'Forming over the Western Carolines, this typhoon moved NNE and then NE passing into the regions of the Aleutian Low.' 
On the other hand, typhoons with many points referenced in their description allow a more detailed and realistic reconstruction of their trajectory; an example in November 1932 (Selga 1935, p. 24-29):

'This typhoon formed halfway between Yap and Palau, moved WNW and inclined NW near Surigao Strait, passing close to, and north of, Guiuan. Crossing Samar in a SE to NW direction, it passed over San Bernardino Strait into
Sorsogon province. Then shifting more to the north, it moved across the hills of southern Tayabas to Hondagua Bay, entering Luzon again between Mauban and Infanta. Over Luzon the centre touched the Provinces of Laguna, Rizal, Bulacan, Nueva Ecija, Nueva Vizcaya, Isabela and Cagayan, passing into the Pacific S of Tuguegarao.'

Fig. 3 shows an analysis of the geographical distribution of typhoon passage frequency. In Fig. 3a this
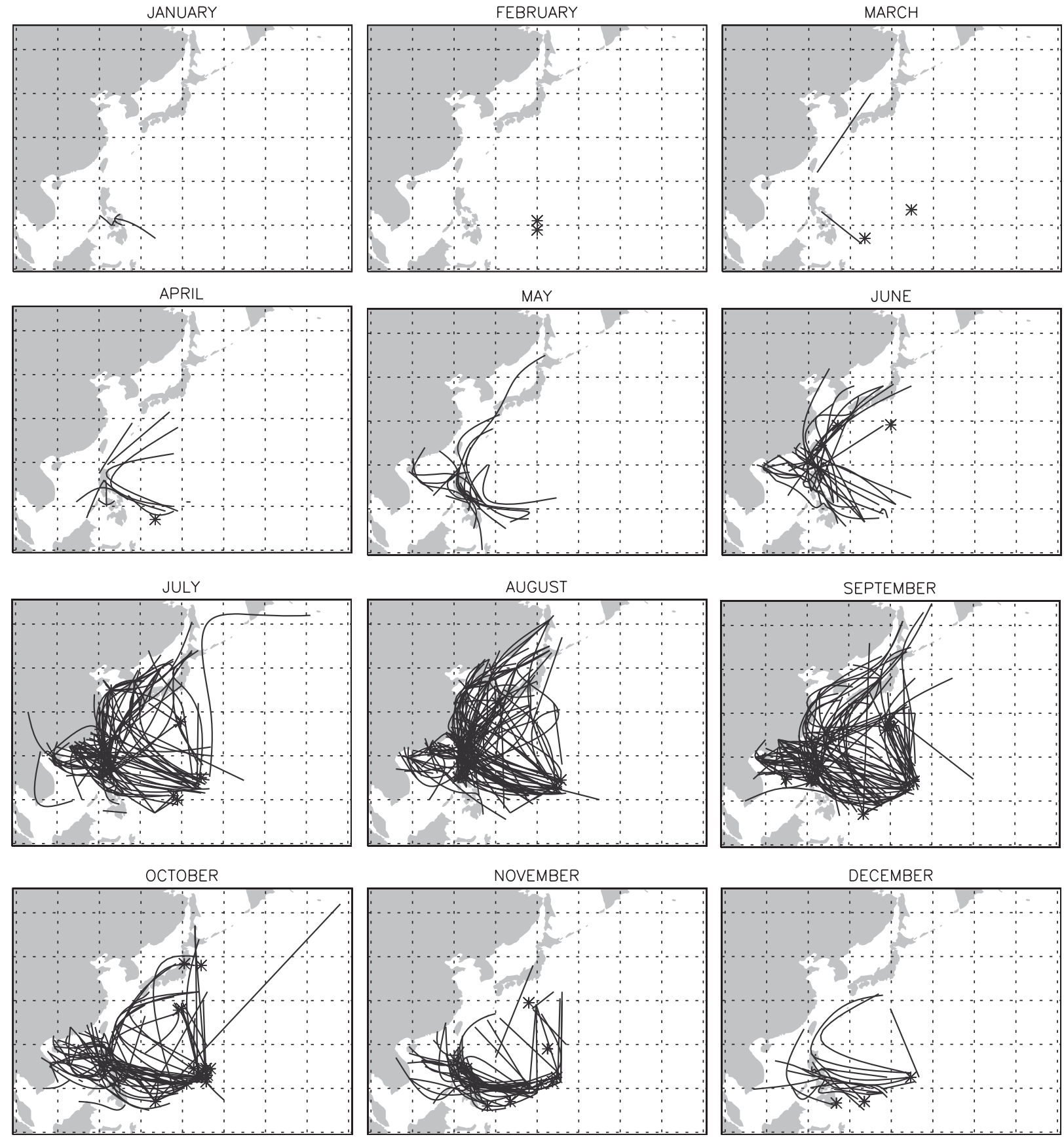

Fig. 2. Monthly composites of typhoon trajectories between 1901 and 1934 (asterisks denote typhoons with a single observation point) 
analysis was done using only points where typhoons were reported in Selga's chronology, while in Fig. 3b the whole estimated trajectories were used. As expected, the highest passage frequency of typhoons is recorded over the archipelago of The Philippines, usually over the northern part of the island of Luzon. This is because most typhoons moved westward and poleward in a curved pathway around the Subtropical Northwestern Pacific High (SNPH), the passage frequency being higher over the South China Sea, Philippine Sea and the coast of SE China. In both Fig. 3a and b, but more markedly in Fig. 3b, the area with the highest frequency of typhoon passage has the shape of an arc that begins near Guam, extends to the west to Luzon, and from there splits in 2 branches: one recurving to the north, towards Japan and Korea; and the other continuing to the west, from Luzon to the Gulf of Tonkin, and covering a wide area of the China Sea. This matches the usual tracks of tropical cyclones in the WNP basin, which form in the Philippine Sea and move westward to terminate over southern China or South Asia, or move poleward and die out over land or over the cold ocean.

Typhoon passage frequencies in Selga's chronology are similar (about $30 \%$ ) to those obtained in recent chronologies (Ho et al. 2004) over the Philippines. For other areas, values obtained for Selga's chronology are lower than those obtained using modern data (1951-2001): over the South China Sea, Selga's chronology indicates about $10 \%$ passage frequency, while modern data show $20 \%$. Over the Philippine Sea, these values are 5 and $25 \%$ respectively; and over the East China Sea they are 10\% for Selga's chronology and $20 \%$ for modern data. The differences are not so marked when the whole reconstructed trajectories are used to compute typhoon passage frequencies (Fig. 3b). This suggests that the reason for this difference is related to the limited area reported in Selga's chronology. Finally, the interdecadal variations reported by Ho et al. (2004), who detected significant increments of the passage frequencies over the South China Sea and significant decreases over the East China Sea and the Philippine
Typhoon Passage Freq. (\%): 1901-1934

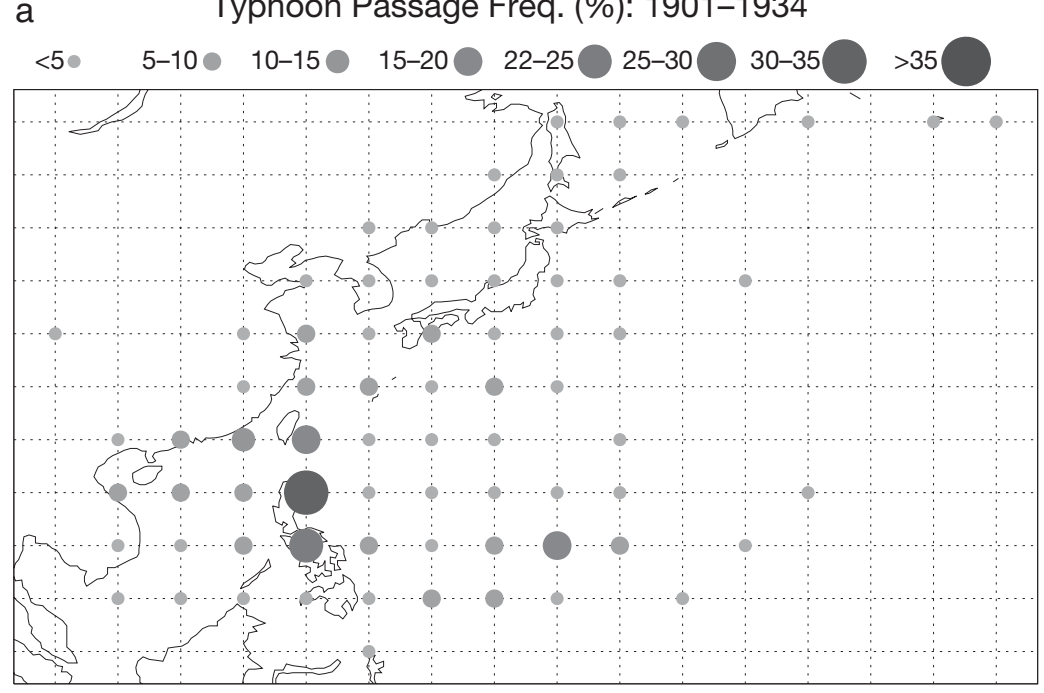

b Typhoon Passage Freq. (\%): 1901-1934

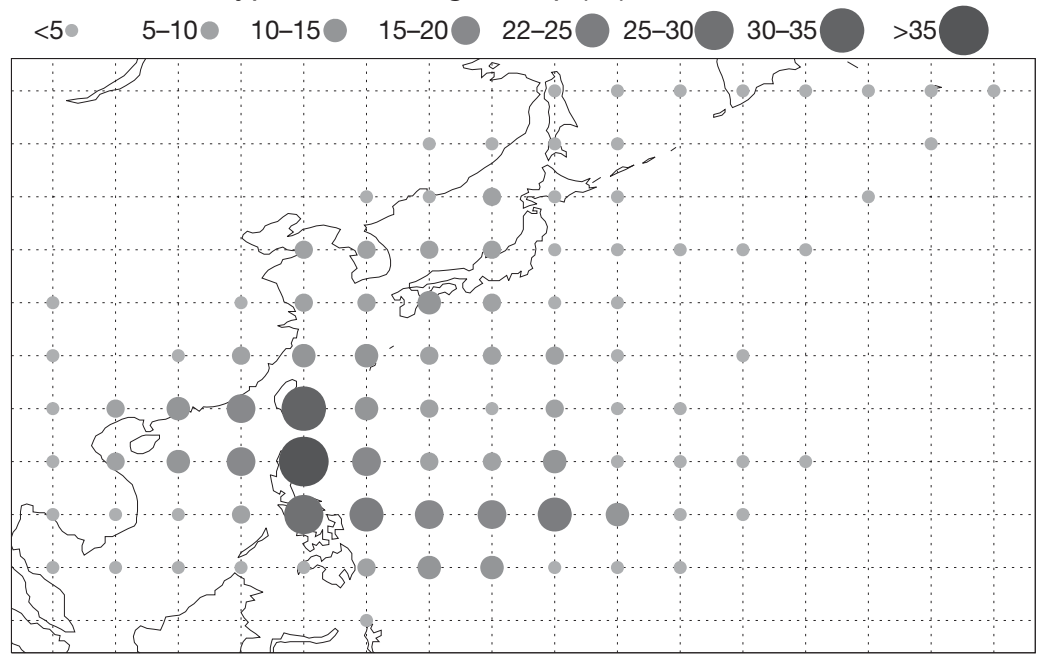

Fig. 3. Geographical distribution of typhoon passage frequency (\%) in each $5^{\circ} \times$ $5^{\circ}$ grid area from Selga's chronology: (a) using only data reported in Selga's chronology; (b) using reconstructed trajectories

Sea since 1970; these are linked to the expansion of the $\mathrm{SNPH}$, and are not found in Selga's chronology.

\section{SUMMARY AND CONCLUSIONS}

Selga's chronology has been presented as a highresolution chronology. It includes complete dating and partial spatial information of the events included, and some instrumental information in more than $30 \%$ of the events catalogued as typhoons. It also includes information about geographical areas affected by each typhoon, from which estimated trajectories were plotted. Although Selga's chronology does not give complete information for tropical cyclone activity 
for the entire WNP, this dataset provides the building blocks for a more thorough reanalysis.

A temporal and spatial comparison between Selga's chronology and a recent instrumental chronology shows some interesting coincidences. The monthly distribution of typhoons is very similar for both chronologies, with maximum occurrence during August and September, and secondarily July and October-but with scarcely any events between January and March.

Selga's chronology overestimates the annual frequency of events over the area. This result is most probably caused by difficulties in identifying as a single typhoon 2 or more of the events cited by Selga as independent-for example, 2 reports from different sources and/or locations. Furthermore, and probably of more consequence, Selga's chronology considered as fully developed typhoons, events which in recent chronologies would be considered as severe storms.

A comparison between the typhoon passage frequencies from Selga's and current chronologies shows reasonable resemblance. They are most similar when the Philippines is analysed independently. In this case, both chronologies identify the highest density of typhoons over the northern and NE coasts of Luzon. This result seems to indicate that Selga's chronology describes in an approximately correct way those typhoons affecting an area relatively close to the Philippines that includes the Archipelago and the continental coasts (both to the south and NE).

Thus, we conclude that Selga's chronology helps to extend by 30 yr the present-day knowledge of typhoon occurrence in the Philippines and part of the WNP area in a reliable way. This will improve characterization of typhoon variability in the region.

Acknowledgements. This study was partially supported by the Risk Prediction Initiative, under Grant RPI02-2-009. The authors thank F. Koek, for providing a copy of the original Selga (1935) paper, and Chris Landsea and 2 anonymous reviewers, whose comments helped us to improve the manuscript.

\section{LITERATURE CITED}

Chang JCL (1985) Tropical cyclone activity in the northwest Pacific in relation to the El Niño/Southern Oscillation phenomenon. Mon Weather Rev 113:599-606

Chang JCL (1995) Tropical cyclone activity in the western North Pacific in relation to the stratospheric quasi-biennial oscillation. Mon Weather Rev 123:2567-2571

Chang JCL (2000) Tropical cyclone activity over the western North Pacific associated with El Niño and La Nina events. J Clim 13:2960-2972

Editorial responsibility: Madhav Khandekar,

Unionville, Ontario, Canada
Chang JCL, Shin JE (2000) Frequency of typhoon landfall over Guandong Province of China during the period 1470-1931. Int J Climatol 20:183-190

Diaz HF, Pulwarty RS (eds) (1997) Hurricanes. Climate and socioeconomic impacts. Springer, Berlin

Donnelly JP, Bryant SS, Butler J, Dowling J and 7 others (2001) 700 year sedimentary record of intense hurricane landfalls in southern New England. Geol Soc Am Bull 113: 714-727

Doyle TW, Gorham LE (1996) Detecting hurricane impact and recovery from tree rings. In: Dean JS, Meko DM, Swetnam TW (eds) Tree rings, environment, and humanity. Radiocarbon, Tucson, AZ, p 405-412

Dvorak WF (1975) Tropical cyclone intensity analysis and forecasting from satellite imagery. Mon Weather Rev 103: $420-430$

Dvorak WF (1984) Tropical cyclone intensity analysis using satellite data. NOAA Tech Rep NESDIS 11

Elsner JB, Bossak BH (2001) Secular changes to the ENSO-US hurricane relationship. Geophys Res Lett 28: 4123-4126

Garcia-Herrera R, Gimeno L, Ribera P, Hernandez E (2005) New records of Atlantic hurricanes from Spanish documentary sources. J Geophys Res 110:D03109 (doi:10.1029/ 2004JD005272)

Ho CH, Baik JJ, Kim JH, Gong D, Sui CH (2004) Interdecadal changes in summertime typhoon tracks. J Clim 17: $1767-1776$

Landsea CW, Nicholls N, Gray WM, Avila LA (1996) Downward trends in the frequency of intense Atlantic hurricanes during the past five decades. Geophys Res Lett 23: $1697-1700$

Liu KB, Fearn ML (2000) Holocene history of catastrophic hurricanes landfalls along the Gulf of Mexico coast reconstructed from coastal lake and marsh sediments. In: Ning $\mathrm{ZH}$, Abdollahi KK (eds) Current stresses and potential vulnerabilities: implications of global change for the Gulf Coast region of the United States. Franklin Press, Baton Rouge, LA

Liu KB, Shen C, Louie KS (2001) A 1000-year history of typhoon landfalls in Guandong, Southern China, reconstructed from Chinese historical documentary records. Ann Assoc Am Geogr 91:453-464

Selga M (1935) Charts of remarkable typhoons in the Philippines 1902-1934. Catalogue of typhoons 1348-1934. Manila Weather Bureau, Manila

Spennemann DHR, Marschner IC (1994) Stormy years: on the association between the El Niño/Southern Oscillation phenomenon and the occurrence of typhoons in the Marshall Islands. Report to the Federal Emergency Management Agency Region IX, San Francisco. The Jonstone Centre of Parks, Recreation and Heritage, Charles Sturt University, Albury, NSW

Udías A (2003) Searching the heavens and the earth: the history of Jesuit observatories. Kluwer Academic Publishers, Dordrecht

Wang B, Chang JCL (2002) How strong ENSO events affect tropical storm activity over the western North Pacific. J Clim 15:1643-1658

Yumoto M, Matsuura T (2001) Interdecadal variability of tropical cyclone activity in the western North Pacific. J Meteorol Soc Jpn 79:23-35

Submitted: September 10, 2004; Accepted: May 20, 2005

Proofs received from author(s): June 18, 2005 